\title{
SOBRE LAS HUMANIDADES EN LA CARRERA DE MEDICINA*
}

\section{Jaime Jaramillo Uribe}

Creo que los llamados cursos de humanidades no deben tener un carácter obligatorio. Para fomentar el interés por la cultura general, me parece que sería más fructífera una amplia extensión cultural en el seno de la Universidad, que incluyera actividades permanentes y bien planeadas de teatro, conciertos, exposiciones de artes plásticas, ciclos de conferencias sobre temas filosóficos, históricos, literarios, científicos, políticos y sociales.

En todo caso, si se decidiere mantener en el plan de estudios médicos cursos obligatorios de humanidades, me parece que no debería existir una posibilidad de elección demasiado amplia. Creo que sería más conveniente limitar la elección a cursos de filosofía, literatura e historia de la cultura y aún actividades artísticas como la música y la pintura. Deben excluirse de este campo las modernas ciencias sociales como la sociología, la economía y la antropología, que son hoy ciencias tan especializadas en métodos y campos de trabajo como pueden serlo las ciencias que constituyen el currículum de las profesiones. No hay duda de que el médico y otros profesionales deberían tomar un curso de sociología o antropología social que les permita comprender los factores sociales que operan en su actividad, pero estas disciplinas deben considerarse como parte técnica y científica de la respectiva profesión y no como meros complementos de ella. En principio, en el estado actual del desarrollo científico, el humanismo puede estar tan ausente de un curso de literatura como de uno de física, y eso es lo que en efecto ha ocurrido en el campo de las ciencias de la cultura que actualmente han adquirido métodos tan sistemáticos y a veces tan mecánicos como los que se consideran propios de las ciencias naturales o físicomatemáticas.

Lo que en mi opinión hay hoy de por medio cuando se habla del contenido humanístico que debe tener toda formación integral del hombre, es la exigencia de que tal formación integral debe incluir un elemento ético y artístico y un conjunto de actitudes como el respeto a la cultura desinteresada, a la tradición y a sus valores éticos y religiosos, la tolerancia y el sentido de la correlación entre las diversas formas de la cultura, que sólo se adquieren o se adquieren más fácilmente cuando entramos en contacto con aquellas actividades que están por fuera de la que practicamos o aprendemos como especialidad o profesión. Pero este contacto, si no es espontáneo y no surge de un impulso individual libre y desinteresado, no tendrá las virtudes formativas que se persiguen.

Por eso me parece que para lograr el resultado de una formación integral, de una educación verdaderamente humanística que no debe confundirse con una educación simplemente erudita ni superficialmente informada — sería más adecuada una amplía actividad cultural extracurricular que motive y suministre al estudiante oportunidades para enriquecer su cultura general en forma libre y espontánea. El humanismo puede ser más bien el resultado de una atmósfera general de la enseñanza que del estudio de esta o aquella disciplina que se considera, muchas veces arbitrariamente, como más humanística que otra.

\footnotetext{
* Inédito, redactado hacia 1966.

Digitalizado por RED ACADEMICA
} 